\title{
Second- and third-generation aromatase inhibitors as first-line endocrine therapy in postmenopausal metastatic breast cancer patients: a pooled analysis of the randomised trials
}

\author{
G Ferretti*,', E Bria', D Giannarelli², A Felici', P Papaldo', A Fabi', S Di Cosimo', EM Ruggeri', M Milella', \\ M Ciccarese', FL Cecere', A Gelibter', C Nuzzo', F Cognetti', E Terzoli' and P Carlini' \\ 'Department of Medical Oncology, Regina Elena Cancer Institute, Rome, Italy; ${ }^{2}$ Biostatistics Unit, Regina Elena Cancer Institute, Rome, Italy
}

\begin{abstract}
The purpose of this study was to estimate in all randomised trials the relative risk of overall response rate (ORR), clinical benefit (CB), time to progression (TTP), overall survival (OS), and toxicity of aromatase inhibitors (Al), compared with tamoxifen (Tam) as first-line endocrine therapy in postmenopausal metastatic breast cancer (PMBC) women. Prospective randomised studies were searched through computerised queries of MEDLINE, EMBASE, and the American Society of Clinical Oncology (ASCO) abstract database. Relative risk, 95\% confidence interval, and heterogeneity were derived according to the inverse variance and Mantel-Haenszel method and $Q$ statistics. Six phase III prospective randomised trials including 2787 women were gathered. A significant advantage in ORR $(P=0.042)$, TTP $(P=0.007)$, and $C B(P=0.001)$ in favour of $A l$ over Tam was detected at the fixed effects model. These results were not significant at the random effects model, owing to the significant heterogeneity. On the contrary, no difference was registered for $O S(P=0.743)$ with no significant heterogeneity. Regarding toxicity, Tam caused more frequently thromboembolic events $(P=0.005)$ and vaginal bleeding $(P=0.00 \mathrm{I})$ compared with Al. Aromatase inhibitors appear to be superior to Tam as first-line endocrine option in PMBC women. Owing to a component of variability between the six studies analysed, the random effects estimates differed from corresponding fixed ones. Investigators should assess heterogeneity of trial results before deriving summary estimates of treatment effect.
\end{abstract}

British Journal of Cancer (2006) 94, I789- |796. doi:I0.I038/sj.bjc.6603I94 www.bjcancer.com

Published online 30 May 2006

(c) 2006 Cancer Research UK

Keywords: aromatase inhibitors; first-line; endocrine therapy; postmenopausal; metastatic breast cancer; pooled analysis

Two-thirds of breast tumours express oestrogen receptor and women having cancers with this characteristic are suitable candidates for endocrine therapy (ET) (Forbes, 1997). Tamoxifen (Tam) has been considered for a long time the drug of choice for postmenopausal women with hormone receptor-positive metastatic breast cancer (MBC). However, Tam is associated with an increased incidence of endometrial cancer and thromboembolic events (TE), and many tumours become resistant to it during treatment (DeFriend et al, 1994). Nowadays, the aromatase inhibitors (AI) are considered the treatment of choice for postmenopausal women with newly diagnosed metastases from hormone receptor-positive breast cancer, either in Tam-naïve patients or in those progressing after failing or while on adjuvant Tam. The AI remarkably suppress plasma oestrogen levels in postmenopausal women by inhibiting or inactivating aromatase,

*Correspondence: Dr G Ferretti, Department of Medical Oncology, Division of Medical Oncology 'A', Regina Elena Cancer Institute, Via Elio Chianesi 53, 00 I44 Rome, Italy; E-mail: gia.fer@flashnet.it

Data partially presented at the 4Ith ASCO Annual Meeting, Orlando 2005.

Received 24 January 2006; revised 3 May 2006; accepted 3 May 2006; published online 30 May 2006 the enzyme responsible for the synthesis of oestrogens from androgenic substrates. Third-generation AI (tgAI), including anastrozole, letrozole, and exemestane, have replaced aminoglutethimide in the treatment of postmenopausal patients with MBC because of their considerably lower toxicity. In addition, tgAI have been reported to be more effective and/or less toxic than megestrol acetate (Buzdar et al, 1998, 2001a; Dombernowsky et al, 1998; Kaufmann et al, 2000) and Tam (Bonneterre et al, 2000, 2001; Mouridsen et al, 2001, 2003; Nabholtz et al, 2000, 2003; Paridaens et al, 2004). As tgAI have been approved as first-line ET for postmenopausal women with $\mathrm{MBC}$, the issue concerning the optimal sequence of ET has become more challenging. In fact, as $\mathrm{AI}$ are more and more frequently used as adjuvant ET, the still open issue concerning the optimal ET sequence will be likely rechallenged in the next future.

A meta-analysis based on patient survival data found a $21 \%$ reduction in the risk of death for patients treated with AI (anastrozole, letrozole, and exemestane) compared with those given megestrol $(P=0.0011)$ (Messori et al, 2000). On the contrary, a pooled analysis has recently suggested that all $\mathrm{AI}$ as second-line ET compared with megestrol for postmenopausal MBC patients do not seem to add any significant advantage in terms of overall response rate (ORR) or time to progression (TTP) (Carlini et al, 
2005). At the present time, the issue as to whether an AI can be more effective than the others remains controversial. Letrozole has been shown to reduce oestrogen levels to a greater degree than the other AI (Boeddinghaus and Dowsett, 2001). Anastrozole has been reported to have greater selectivity for aromatase (Buzdar $2001 \mathrm{~b}$ ), but it is still uncertain whether these laboratory findings could affect the clinical decision of preferring one drug instead of another.

The aim of this meta-analysis was to estimate in all published randomised trials the relative risk (RR) of ORR, TTP, clinical benefit (CB), overall survival (OS) and, whenever possible, adverse events of AI compared with Tam as first-line ET in postmenopausal women with MBC.

\section{MATERIALS AND METHODS}

\section{Outcome definition}

We considered the AI as experimental arm and Tam as standard comparator arm. Analysis was conducted in order to find out eventual significant differences in primary and secondary outcomes. Primary outcomes were (1) ORR and (2) TTP. The secondary outcomes were $\mathrm{OS}, \mathrm{CB}$, and toxicity, evaluated in at least three trials. In particular, we looked at hot flushes (HF), nausea $(\mathrm{N})$, vomiting $(\mathrm{V})$, TEs, vaginal bleeding $(\mathrm{VB})$, and musculoskeletal pain (MSP). All calculations were independently performed by two different investigators. The definition of CB (British Breast Group, 1974) was the same across all trials.

\section{Trial identification criteria}

We collected all the prospective randomised trials published as formal papers in peer-reviewed journals or as abstracts in the international congresses proceedings until 31 December, 2004 (Perez Carrion et al, 1994; Falkson and Falkson, 1996; Thurlimann et al, 1996; Bonneterre et al, 2000; Nabholtz et al, 2000; Mouridsen et al, 2001; Milla-Santos et al, 2003; Paridaens et al, 2004) (Table 1). In these trials, postmenopausal patients affected by MBC relapsing after adjuvant therapy were randomised to receive AI $v s$ standard treatment (Tam). Letters/editorials, studies on AI given as adjuvant/neoadjuvant ET were ruled out.

\section{Search strategy}

Relevant studies were searched through computerised queries of MEDLINE (available from URL: www.ncbi. nlm.nih.gov/PubMed), EMBASE (available from URL: www.embase.com), and the
American Society of Clinical Oncology (ASCO) abstract database (available from URL: www.asco.org). Keywords used for research were metastatic breast cancer, aromatase inhibitors, first-line, AI, steroidal, non-steroidal, anastrozole, fadrozole, letrozole, exemestane, formestane, review, metanalysis, meta-analysis, pooled analysis, randomised, phase III, comprehensive review, systematic review, hormonal, and endocrine. Beyond computer browsing, review and original papers were also scanned in the references section to look for missing trials. From each study we obtained (1) rate and number of complete and partial responses, (2) CB (British Breast Group, 1974), (3) median TTP, (4) median OS and (5) rate and number of toxicity events.

\section{Statistical methods}

The $\log$ of $\mathrm{RR}$ was estimated for each considered end point. Estimated events at 6 months were used when considering TTP and OS. These RRs were combined across the studies, giving weight to the number of events in each of the two treatment groups in each separate study using the Mantel-Haenszel procedure and the inverse variance method; both estimations were performed assuming a fixed effects model (FEM) and a random effects model (REM) (Parmar et al, 1998). The heterogeneity between trials was tested with the $Q$ statistics, computing the square distance of each study from the combined effect and weighting these values with the inverse of variance of each study (Takkouche et al, 1999). The $Q$ statistics was then compared with the $\chi^{2}$ distribution with $k-1$ degrees of freedom, where $k$ is the number of studies. All calculations were performed with the Comprehensive Metaanalysis software (version 1.0.23, Biostat, Englewood, NJ, USA) (Bria et al, 2005).

\section{RESULTS}

\section{Selected trials}

The eight prospective randomised trials comparing AI vs Tam (Perez Carrion et al, 1994; Falkson and Falkson, 1996; Thurlimann et al, 1996; Bonneterre et al, 2000; Nabholtz et al, 2000; Mouridsen et al, 2001; Milla-Santos et al, 2003; Paridaens et al, 2004) were conducted between 1994 and 2004, and included 3238 women (Table 1). Globally, 1615 patients were enrolled in the AI arm and 1623 in Tam arm. The median number of patients per trial was 362 (range 80-907). The median follow-up time, when reported, varied much among trials (between 5.1 and 36 months) (Table 1). In the $\mathrm{AI}$ arm, TTP ranged between 7.1 and 18 months, and in the Tam arm, between 5.6 and 9.8 months. In the AI arm, the OS range

Table I Characteristics of the studies

\begin{tabular}{|c|c|c|c|c|c|c|}
\hline RCTs & Year & Pts & Arms & Primary/secondary end points & $\begin{array}{l}\text { Median follow- } \\
\text { up (months) }\end{array}$ & Key results \\
\hline Perez Carrion & 1994 & 409 & FOR vs TAM & ORR (UICC)/TTP, TTF, OS, safety & NR & $\begin{array}{l}\text { No difference in ORR and OS, longer TTP and } \\
\text { TTF in the TAM arm }\end{array}$ \\
\hline Thurlimann & 1996 & 212 & FDZ vs TAM & ORR (WHO)/TTF, OS, safety & 36 & $\begin{array}{l}\text { Not double-blinded, no difference in ORR and } \\
\text { OS, longer TTF in the TAM arm }\end{array}$ \\
\hline Falkson & 1996 & 80 & FDZ vs TAM & ORR (ECOG)/TTF, OS, safety & 5.1 & No difference in ORR, TTF, and OS \\
\hline Nabholtz & 2000 & 353 & ANA vs TAM & ORR (UICC), TTP, safety/TTF, CB, OS & 17.7 & $\begin{array}{l}\text { No difference in ORR, longer TTP, and higher CB } \\
\text { in the ANA arm }\end{array}$ \\
\hline Bonneterre & 2000 & 668 & ANA vs TAM & ORR (UICC), TTP, safety/TTF, CB, OS & 19 & No difference in ORR, TTP, and CB \\
\hline Mouridsen & 2001 & 907 & LTZ vs TAM & TTP/ORR (UICC), TTF, CB, OS, safety & 32 & Longer TTP, higher ORR and CB in the LTZ arm \\
\hline Milla Santos & 2003 & 238 & ANA vs TAM & CB, ORR (WHO), TTP, OS, safety & 13.3 & Longer TTP and OS, higher CB, in the ANA arm \\
\hline $\begin{array}{l}\text { Paridaens } \\
\text { Total }\end{array}$ & 2004 & $\begin{array}{r}371 \\
3238\end{array}$ & EXE vs TAM & PFS/OS, safety & NR & Longer PFS, higher ORR in the EXE arm \\
\hline
\end{tabular}

$\mathrm{ANA}=$ anastrozole; $\mathrm{CB}=$ clinical benefit; $\mathrm{EXE}=$ exemestane; $\mathrm{FDZ}=$ fadrozole; $F \mathrm{OR}=$ formestane; $\mathrm{LTZ}=$ letrozole; $N R=\mathrm{not}$ reported; $\mathrm{ORR}=\mathrm{overall}$ response rate; $\mathrm{OS}=$ overall survival; PFS = progression-free survival; pts = patients; RCTs = randomised clinical trials; TAM=tamoxifen; TTF=time to treatment failure; TTP = time to progression. 
varied between 17.4 and 39.2 months, and in the Tam arm, between 16 and 40 months. In the AI arm, CB ranged between 50 and $83 \%$, and in the Tam arm, between 38 and $75.7 \%$. Hot flushes rate was reported in all trials (3238 patients), $\mathrm{N}$ in six trials (Perez Carrion et al, 1994; Thurlimann et al, 1996; Bonneterre et al, 2000; Nabholtz et al, 2000; Mouridsen et al, 2001; Paridaens et al, 2004) (2920 patients), V in five trials (Perez Carrion et al, 1994; Thurlimann et al, 1996; Bonneterre et al, 2000; Nabholtz et al, 2000; Paridaens et al, 2004) (2012 patients), TE in six trials (Thurlimann et al, 1996; Bonneterre et al, 2000; Nabholtz et al, 2000; Mouridsen et al, 2001; Milla-Santos et al, 2003; Paridaens et al, 2004) (2749 patients), VB in four trials (Bonneterre et al, 2000; Nabholtz et al, 2000; Milla-Santos et al, 2003; Paridaens et al, 2004) (1630 patients), and MSP in four trials (Bonneterre et al, 2000; Nabholtz et al, 2000; Milla-Santos et al, 2003; Paridaens et al, 2004) (2299 patients). The primary and secondary end points are indicated in Table 1. All arms within each trial were well balanced for pretreatment characteristics of the patients.

For our meta-analysis, we selected only the phase III studies published as original papers in peer-review journals. These studies (Perez Carrion et al, 1994; Thurlimann et al, 1996; Bonneterre et al, 2000; Nabholtz et al, 2000; Mouridsen et al, 2001; Milla-Santos et al, 2003) globally included 2787 women. The trial by Falkson and Falkson (1996), which was a randomised phase II study, was excluded. The study by Paridaens et al (2004), which was a large randomised phase III trial presented at the 2004 ASCO annual meeting but published exclusively in the abstract format, was included only in the comparisons (efficacy and toxicity) between tgAI vs Tam.

\section{Combined analysis}

All outcomes and their statistical significance are listed in Table 2. Risk ratios have to be interpreted as follows: regarding ORR and $\mathrm{CB}, \mathrm{RR}$ more than 1.0 favours AI, whereas RR less than 1.0 favours Tam; concerning TTP and OS, RR less than 1.0 favours AI, whereas RR more than 1.0 favours Tam (event-based analysis, see Statistical methods).

We compared AI vs Tam in the overall population (2787 patients), using the FEM first. A significant advantage in ORR in favour of AI over Tam was detected $(\mathrm{RR}=1.13,95 \%$ confidence interval (CI) $1.00-1.28, P=0.042$ ) (Table 2 and Figure 1 ). The same impact in favour of AI was seen for TTP (2549 patients), where RR was 0.88 (95\% CI $0.80-0.96, P=0.007)$ (Table 2 and Figure 2). Moreover, concerning $\mathrm{CB}$, a statistically significant advantage in favour of AI compared with Tam was observed (RR

Table 2 Efficacy: aromatase inhibitors vs tamoxifen (FEM and REM)

\begin{tabular}{lccccccccc}
\hline & RCTs & Pts & RR (FEM) & RR (REM) & 95\% CI (FEM) & 95\% CI (REM) & P (FEM) & Het. & P (REM) \\
\hline ORR & 6 & 2787 & 1.13 & 1.11 & $1.00,1.28$ & $0.89,1.37$ & 0.042 & 0.03 \\
TTP & 5 & 2549 & 0.88 & 0.92 & $0.80,0.96$ & $0.68,1.26$ & 0.007 & $<0.0001$ \\
CB & 6 & 2787 & 1.11 & 1.13 & $1.04,1.19$ & $0.96,1.33$ & 0.001 & $<0.0001$ \\
OS & 6 & 2787 & 0.97 & & $0.79,1.18$ & & 0.637 & 0.123 \\
\hline
\end{tabular}

$\mathrm{Cl}=$ confidence intervals; $\mathrm{FEM}=$ fixed effects model; Het = heterogeneity; ORR = overall response rate; OS = overall survival; Pts = patients; RCTs = randomised clinical trials; $\mathrm{REM}=$ random effects model; $\mathrm{RR}=$ relative risk ratio; $T \mathrm{TP}=$ time to progression.

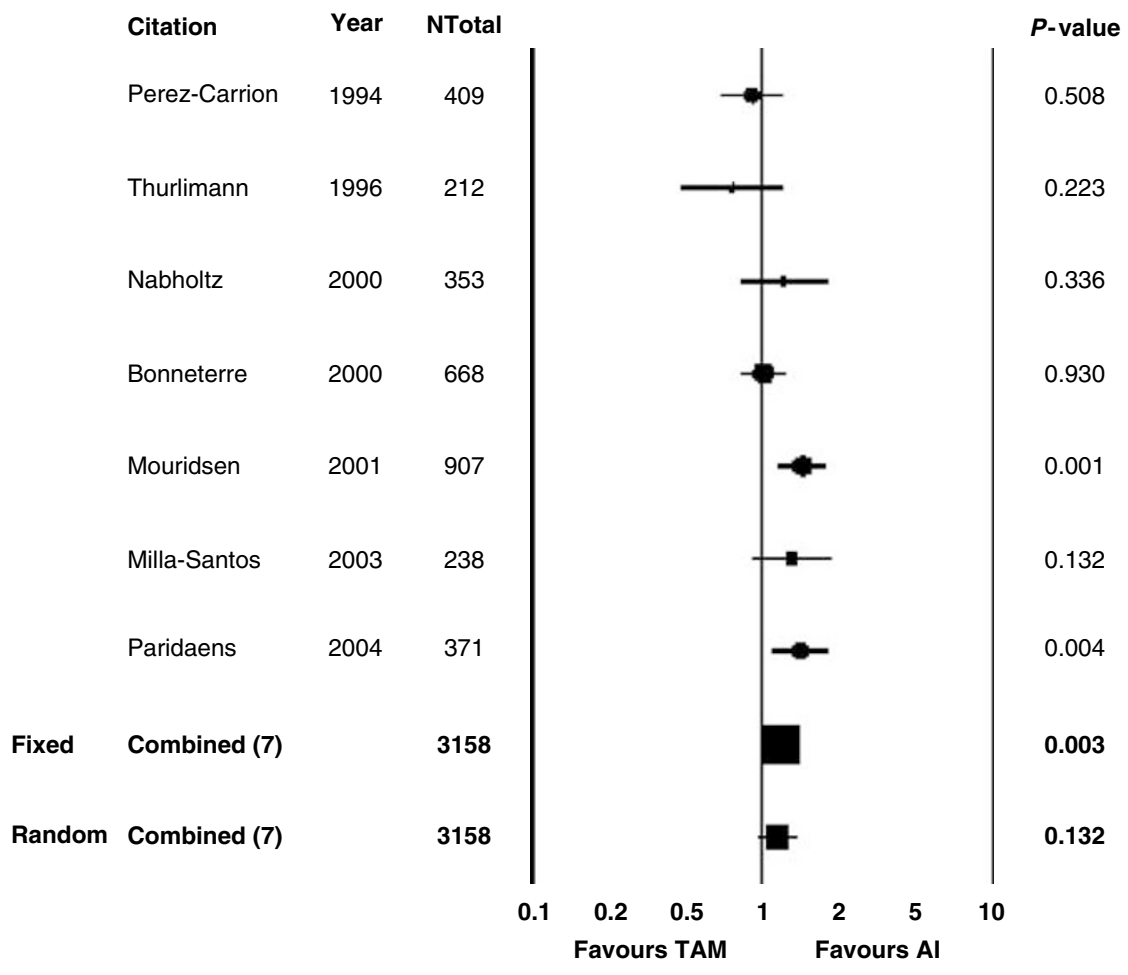

Figure I Aromatase inhibitors vs tamoxifen: ORR. Al: aromatase inhibitors; TAM: tamoxifen; Ntot: total number of patients; RR: relative risk; Fixed: fixed effects model; Random: random effects model; ORR: overall response rate. 


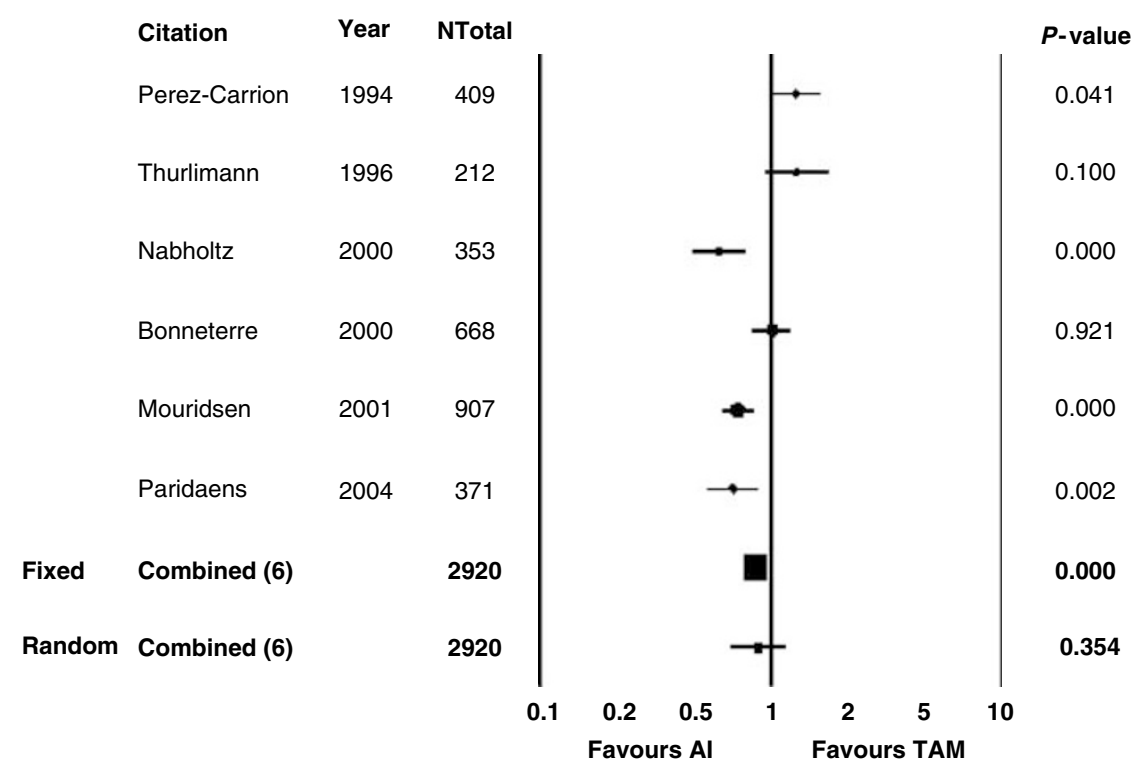

Figure 2 Aromatase inhibitors vs tamoxifen: TTP. Al: aromatase inhibitors; TAM: tamoxifen; Ntot: total number of patients; RR: relative risk; Fixed: fixed effects model; Random: random effects model.

Table 3 Efficacy: non-steroidal aromatase inhibitors vs tamoxifen (FEM and REM)

\begin{tabular}{|c|c|c|c|c|c|c|c|c|c|}
\hline & RCTs & Pts & RR (FEM) & RR (REM) & 95\% Cl (FEM) & 95\% Cl (REM) & $P($ FEM) & Het. & $P$ (REM) \\
\hline TTP & 3 & 1928 & 0.77 & 0.76 & $0.69,0.86$ & $0.55,1.05$ & $<0.0001$ & 0.002 & 0.098 \\
\hline
\end{tabular}

$\mathrm{Cl}=$ confidence intervals; FEM: fixed effects model; Het $=$ heterogeneity; $\mathrm{ORR}=$ overall response rate; $\mathrm{OS}=$ overall survival; Pts $=$ patients; $\mathrm{RCT} s=$ randomised clinical trials; $\mathrm{REM}=$ random effects model; $\mathrm{RR}=$ relative risk ratio; $\mathrm{TTP}=$ time to progression

Table 4 Efficacy: third-generation aromatase inhibitors vs tamoxifen (FEM and REM)

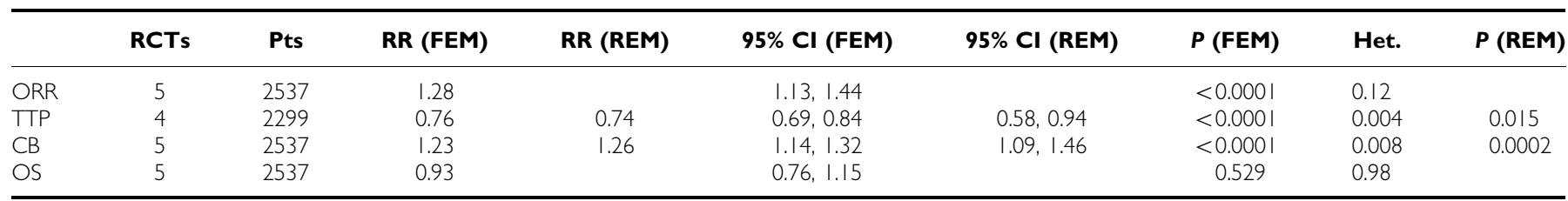

$\mathrm{Cl}=$ confidence intervals; $\mathrm{FEM}=$ fixed effects model; Het = heterogeneity; ORR = overall response rate; OS = overall survival; Pts = patients; RCTs = randomised clinical trials; $\mathrm{REM}=$ random effects model; $\mathrm{RR}=$ relative risk ratio; $\mathrm{TTP}=$ time to progression

$1.11,95 \%$ CI $1.04-1.19, P=0.001)$. On the contrary, no significant difference was registered for OS (RR $0.97,95 \%$ CI $0.79-1.18$, $P=0.743)$ (Table 2). A significant heterogeneity for ORR (0.03), TTP $(<0.0001)$, and CB $(<0.0001)$ was registered using the FEM (Table 2). At the REM, the significant improvement in ORR, TTP, and $\mathrm{CB}$ in favour of $\mathrm{AI}$ over Tam was not confirmed. By contrast, no significant heterogeneity was observed regarding OS estimates (Table 2).

Comparing non-steroidal AI (nsAI) vs Tam using the FEM, a significant advantage in ORR favouring nsAI vs Tam was registered $(\mathrm{RR}=1.23,95 \% \mathrm{CI} 1.07-1.42, P=0.003)$ (Table 3$)$. The same advantage in favour of nsAI was seen for TTP, where RR was $0.77(95 \%$ CI $0.69-0.86, P=<0.0001)$. A statistically significant result was observed also for CB in favour of nsAI over Tam (RR 1.21, 95\% CI 1.12-1.31, $P<0.0001$ ). No significant difference was registered for OS (RR $0.94,95 \%$ CI $0.75-1.78$, $P=0.599$ ) (Table 3). A significant heterogeneity for TTP $(0.002)$ and CB (0.005) was registered at the FEM (Table 3). When the REM was used, only the improvement in $\mathrm{CB}$ was confirmed. No significant heterogeneity was observed regarding OS estimates (Table 3).

Comparing tgAI $v s$ Tam by the fixed effects estimate (FEM), a significant advantage in ORR favouring tgAI $v s$ Tam was observed $(\mathrm{RR}=1.28,95 \%$ CI $1.13-1.44, P<0.0001)$ (Table 4). The same advantage in favour of tgAI was seen for TTP, where RR was 0.76 (95\% CI 0.69-0.84, $P<0.0001)$. A statistically significant advantage was observed also for CB in favour of tgAI over Tam (RR 1.23, 95\% CI 1.14-1.32, $P<0.0001)$. No significant difference was registered for OS (RR $0.93,95 \%$ CI $0.76-1.15, P=0.529$ ) (Table 4). A significant heterogeneity for TTP (0.004) and CB (0.008) was registered at the FEM (Table 4). Using the REM, the significant improvement in TTP and CB in favour of AI over Tam was confirmed. No significant heterogeneity was observed regarding OS estimates (Table 4).

Regarding toxicity at the FEM, Tam caused more frequently TE (RR $0.53,95 \%$ CI $0.34-0.82, P=0.005)$ and VB (RR 0.33, 95\% CI 
$0.17-0.65, P=0.001$ ) (Table 5 and Figures 3 and 4 ). No significant difference was observed in HF $(P=0.171), \mathrm{N} \quad(P=0.547), \mathrm{V}$ $(P=0.686)$, and MSP $(P=0.598)$ (Table 5). Similar results were

Table 5 Toxicity: aromatase inhibitors vs tamoxifen (FEM)

\begin{tabular}{lcccccc}
\hline & RCTs & Pts & RR & $\mathbf{9 5 \%} \mathbf{C l}$ & $\boldsymbol{P}$ & Het. \\
\hline HF & 6 & 2787 & 1.11 & $0.95,1.30$ & 0.171 & 0.06 \\
Nausea & 5 & 2549 & 0.94 & $0.78,1.13$ & 0.547 & 0.67 \\
Vomiting & 4 & 1642 & 1.08 & $0.72,1.62$ & 0.686 & 0.49 \\
TE & 5 & 2378 & 0.53 & $0.34,0.82$ & 0.005 & 0.42 \\
VB & 3 & 1259 & 0.33 & $0.17,0.65$ & 0.001 & 0.71 \\
MSP & 3 & 1928 & 1.05 & $0.87,1.26$ & 0.598 & 0.79 \\
\hline
\end{tabular}

$\mathrm{Cl}=$ confidence intervals; FEM = fixed effects model; Het = heterogeneity; $\mathrm{HF}=$ hot flushes; $M S P=$ muscolo-skeletal pain; $O R R=$ overall response rate; $O S=$ overall survival; Pts = patients; $R C T s=$ randomised clinical trials; $R E M=$ random effects model; RR = relative risk ratio; TE: thromboembolic events; VB: vaginal bleeding. observed comparing nsAI vs Tam (Table 6) or tgAI vs Tam (Table 7). Excluding HF, no significant heterogeneity was registered concerning toxicity, in particular with respect to TE and VB (Table 4). Regarding HF reported using nsAI or tgAI $v s$ Tam, the findings reported by the FEM were confirmed at the REM.

\section{DISCUSSION}

The AI have been reported to be superior to Tam as initial therapy for postmenopausal women with MBC (Nabholtz et al, 2000; Bonneterre et al, 2001; Mouridsen et al, 2001, 2003; Paridaens et al, 2004). Our analysis of abstracted data coming from six trials using AI as first-line endocrine option in comparison with Tam in postmenopausal women with $\mathrm{MBC}$ detected a statistically significant improvement in ORR, $\mathrm{CB}$, and TTP in favour of AI over Tam (FEM). These results were not significant at the REM, owing to the strongly significant heterogeneity (Table 2 and Figure 1 and

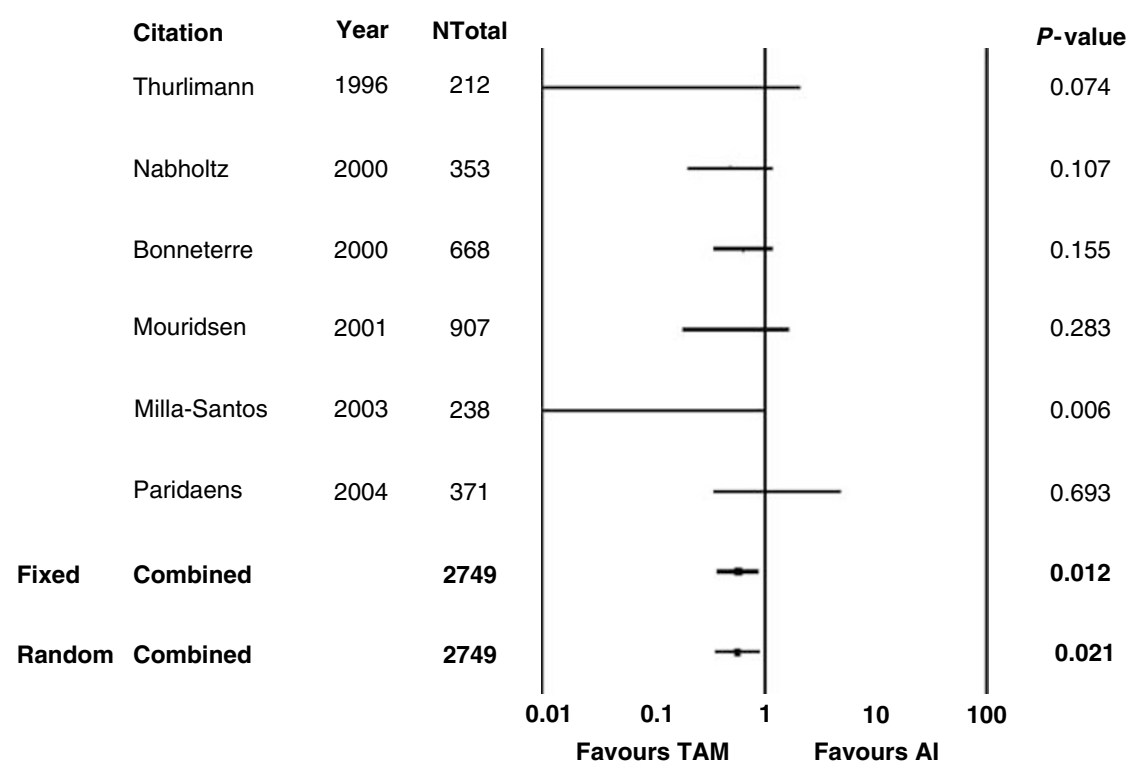

Figure 3 Aromatase inhibitors vs tamoxifen: TEs. Al: aromatase inhibitors; TAM: tamoxifen; Ntot: total number of patients; RR: relative risk; Fixed: fixed effects model; Random: random effects model.

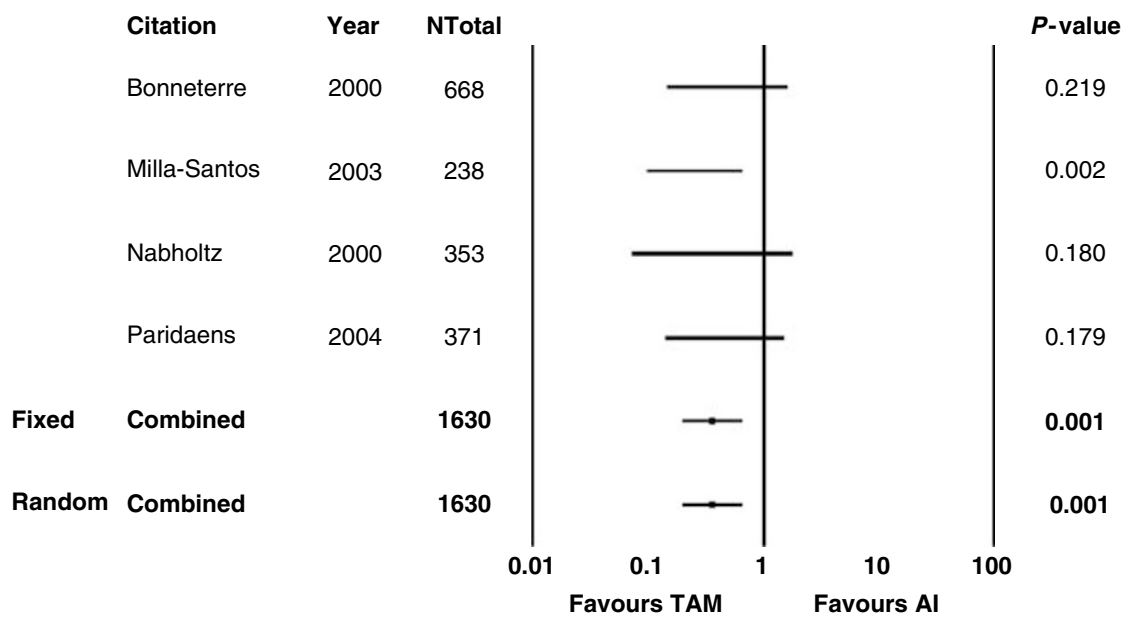

Figure 4 Aromatase inhibitors vs tamoxifen: VB. Al: aromatase inhibitors; TAM: tamoxifen; Ntot: total number of patients; RR: relative risk; Fixed: fixed effects model; Random: random effects model. 
Table 6 Toxicity: non-steroidal aromatase inhibitors vs tamoxifen (FEM and REM)

\begin{tabular}{|c|c|c|c|c|c|c|c|c|c|}
\hline & RCTs & Pts & RR (FEM) & RR (REM) & 95\% Cl (FEM) & 95\% Cl (REM) & $P$ (FEM) & Het. & $P$ (REM) \\
\hline Nausea & 3 & 1928 & 0.94 & & $0.78,1.13$ & & 0.530 & 0.85 & \\
\hline TE & 4 & 2166 & 0.55 & & $0.35,0.86$ & & 0.009 & 0.43 & \\
\hline VB & 3 & 1259 & 0.33 & & $0.17,0.65$ & & 0.001 & 0.71 & \\
\hline MSP & 3 & 1928 & 1.05 & & $0.87,1.26$ & & 0.598 & 0.79 & \\
\hline
\end{tabular}

$\mathrm{Cl}=$ confidence intervals; FEM = fixed effects model; Het = heterogeneity; HF= hot flushes; MSP = muscolo-skeletal pain; ORR = overall response rate; OS = overall survival; $\mathrm{Pts}=$ patients; $\mathrm{RCTs}=$ randomised clinical trials; $\mathrm{REM}=$ random effects model; $\mathrm{RR}=$ relative risk ratio; $\mathrm{TE}=$ thromboembolic events; $\mathrm{VB}=\mathrm{vaginal}$ bleeding.

Table 7 Toxicity: third-generation aromatase inhibitors vs tamoxifen (FEM and REM)

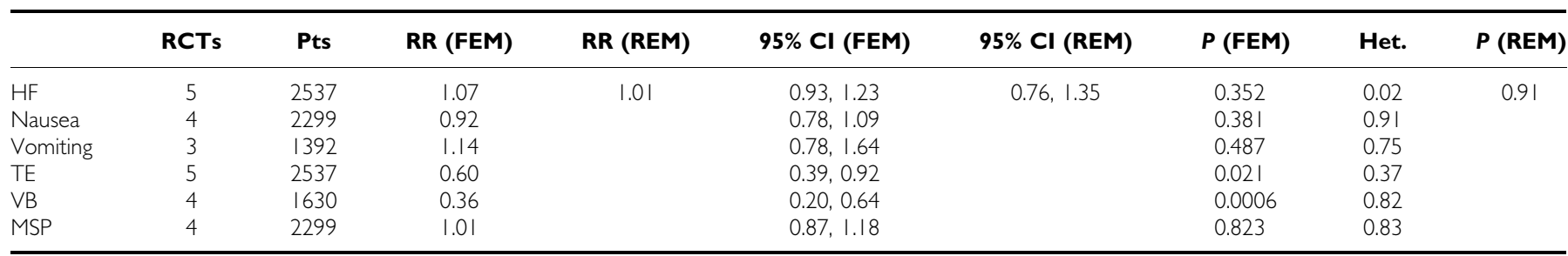

$\mathrm{Cl}=$ confidence intervals; FEM = fixed effects model; Het = heterogeneity; HF = hot flushes; MSP = muscolo-skeletal pain; ORR = overall response rate; OS = overall survival; Pts = patients; $R C T s=$ randomised clinical trials; $R E M=$ random effects model; $R R=$ relative risk ratio; $T E=$ thromboembolic events; $V B=$ vaginal bleeding.

2). Stratifying for type of AI (steroidal and non-steroidal), a significant difference (FEM) in ORR, CB, and TTP in favour of nsAI over Tam was observed as well. At the REM, only the improvement in CB was confirmed, whereas the advantage in TTP lost its significance (Table 3). Fadrozole (Tominaga et al, 2003) and formestane (Vorobiof et al, 1999) have been shown to be inferior to letrozole and anastrozole, respectively. For this reason, we excluded fadrozole and formestane studies from the analysis of AI $v s$ Tam, in order to make the differences greater. Comparing tgAI vs Tam, a significant difference (FEM) in ORR, CB, and TTP in favour of tgAI over Tam was observed. It must be highlighted that the results concerning TTP and CB maintained their significance at the REM, despite the significant heterogeneity (Table 4). By contrast, there was no clear evidence of benefit in OS comparing AI with Tam, without significant heterogeneity. However, OS estimation in MBC could be affected by several factors, such as prior or subsequent chemotherapy or hormonal treatments or crossover design, and TTP might be regarded as the most sensitive parameter to assess efficacy of a new drug, especially when TTP increase is associated with ORR increase (Di Leo and Bleiberg, 2003). Finally, owing to the above-mentioned significant heterogeneity, any definitive conclusion about ORR, TTP, and CB cannot be conclusively affirmed.

The availability of results using both the REM and FEM in electronic publications could represent a temptation to select the model that better supports the authors' hypothesis, introducing a potential source of bias in the interpretation of meta-analysis results. Heterogeneity is an important issue in meta-analyses. When there is no component of variability between studies, the results of methods based on FEM or REM are essentially identical and both methods yield similar point estimates (Greenland, 1987; Berlin et al, 1989). When there is heterogeneity between studies, fixed effects standard errors often suggest inappropriate precision and the CI for a summary estimate of effects size will be wider when the random effect is used. Thus, as heterogeneity is incorporated directly into random effects summary estimates and their standard errors, it is not surprising that random effects estimates sometimes differ from corresponding fixed effects ones (Engels et al, 2000). The overall effect of heterogeneity could be to make most random effects estimates less significant than the corresponding fixed effects estimates. The REM assumption that trials included in a meta-analysis are a random sample from a large population of trials would seem to be less defendable in the context of systematic reviews, which, by definition, aim at the inclusion of all published and unpublished trials considered as the population from which this assumption is being inferred (Villar et al, 2001). The REM inference concerning parameters of a population larger than those trials available, including trials that may be carried out later, does not seem relevant in the context of meta-analyses conducted as part of systematic reviews of randomised controlled trials. Such reviews explore mostly the question as to whether the treatment can produce benefit on average in the studies at hand (Bailey, 1987). Finally, several authors present arguments for and against routine use of models based on REM or FEMs in metaanalysis (Greenland, 1987; Peto, 1987; Berlin et al, 1989; Thompson and Pocock, 1991), but there is no clear consensus yet.

Heterogeneity is not only statistical per se, but is also closely related to the study design of the systematic review, the nature of the trials included, the intended extrapolation of the results, and the clinical relevance of the observed differences. Therefore, systematic reviews might locate all available trials (even if unpublished) and make extensive efforts to include them, similar to the efforts typically made to reduce loss to follow-up in clinical trials. In the presence of statistical heterogeneity, the main focus of a meta-analysis should be on trying to understand clinical sources of heterogeneity. The significant heterogeneity, which proves trial interaction, could easily depend on different patients selection (i.e., differences in the characteristics of study subjects, such as their mean age and the severity of illness, positive or unknown receptor status, node-negative or node-positive disease), different trial designs, different rates of loss to follow-up, different interventions (dose or duration of treatment), or outcome measures. For example, the study by Mouridsen et al (2001) had almost twice as many patients with prior Tam therapy than the study by Bonneterre et al (2000) and Nabholtz et al (2000) (22 vs 7.6 vs $11.6 \%$ total) (Copur et al, 2001). In four studies (Falkson and Falkson, 1996; Thurlimann et al, 1996; Mouridsen et al, 2001; Paridaens et al, 2004), more than $30 \%$ of the patients had previously received chemotherapy, whereas in other three studies (Falkson and Falkson, 1996; Bonneterre et al, 2000; Nabholtz et al, 
2000), this percentage ranged between 5 and $21 \%$. In five trials (Thurlimann et al, 1996; Nabholtz et al, 2000; Mouridsen et al, 2001; Milla-Santos et al, 2003; Paridaens et al, 2004), more than $65 \%$ of the patients had hormone receptor-positive tumours compared with only $43 \%$ in the three remainder studies (Perez Carrion et al, 1994; Falkson and Falkson, 1996; Bonneterre et al, 2000). Conversely, most of the patients in the study by Bonneterre et al (2000) $(54.4 \%$ in the anastrozole group and $55.8 \%$ in the tamoxifen group) had tumours with unknown hormone receptors, whereas Nabholtz et al (2000) reported only 11.1 and $11 \%$ and Mouridsen et al (2001) 34 and 33\%, respectively (Costa and Kaufmann, 2001). Almost $50 \%$ of the patients in the study by Bonneterre et al (2000) had advanced-stage disease at presentation and therefore had received no prior treatment. This is $20 \%$ more than for the women in the North American study (Nabholtz et al, 2000) and $25 \%$ more than for patients in the Mouridsen et al's (2001) study. The group of patients in the study by Bonneterre et al (2000) had $88 \%$ measurable disease, compared with $68-76 \%$ measurable disease as in the North American patients (Nabholtz et al, 2000). More importantly, in Nabholtz et al's (2000) study, the tamoxifen group had an excess of patients with liver disease (16.5\%) (Tonkin, 2001) compared with Bonneterre et al's (2000) study (9.5\%) and Mouridsen et al's (2001) study (viscera only $13 \%)$.

Concerning toxicity, we chose the most frequently reported side effects (at least in three trials), in order to obtain reliable comparisons between AI and Tam. Thus, toxicity was not evaluated completely, and, for this reason, the reported results must be interpreted cautiously. The analysed adverse events were

\section{REFERENCES}

Bailey K (1987) Inter-study differences: how should they influence the interpretation and analysis of results. Stat Med 6: 351-358

Berlin JA, Laird NM, Sacks HS, Chalmers TC (1989) A comparison of statistical methods for combining event rates from clinical trials. Stat Med 8: $141-151$

Boeddinghaus IM, Dowsett M (2001) Comparative clinical pharmacology and pharmacokinetic interactions of aromatase inhibitors. J Steroid Biochem Mol Biol 79: 85-91

Bonneterre J, Buzdar A, Nabholtz JM, Robertson JF, Thurlimann B, von Euler M, Sahmoud T, Webster A, Steinberg M (2001) Anastrozole is superior to tamoxifen as first-line therapy in hormone receptor positive advanced breast carcinoma. Cancer 92: 2247-2258

Bonneterre J, Thurlimann B, Robertson JF, Krzakowski M, Mauriac L, Koralewski P, Vergote I, Webster A, Steinberg M, von Euler M (2000) Anastrozole $v s$ tamoxifen as first-line therapy for advanced breast cancer in 668 postmenopausal women: results of the TARGET (Tamoxifen or Arimidex Randomised Group Efficacy and Tolerability) study. J Clin Oncol 18: $3748-3757$

Bria E, Giannarelli D, Felici A, Peters WP, Nisticò C, Vanni B, Cuppone F, Cognetti F, Terzoli E (2005) Taxanes with anthracyclines as first-line chemotherapy for metastatic breast carcinoma: pooled analysis of 2805 patients. Cancer 103(4): 672-679

British Breast Group (1974) Assessment of response to treatment in advanced breast cancer. Lancet 2: $38-39$

Buzdar AU, Jonat W, Howell A, Jones SE, Blomqvist CP, Vogel CL, Eiermann W, Wolter JM, Steinberg M, Webster A, Lee D (1998) Anastrozole $v s$ megestrol acetate in the treatment of postmenopausal women with advanced breast carcinoma: results of a survival update based on a combined analysis of data from two mature phase III trials Arimidex Study Group. Cancer 83: $1142-1152$

Buzdar A, Douma J, Davidson N, Elledge R, Morgan M, Smith R, Porter L, Nabholtz J, Xiang X, Brady C (2001a) Phase III, multicenter, doubleblind, randomized study of letrozole, an aromatase inhibitor, for advanced breast cancer $v$ s megestrol acetate. J Clin Oncol 19: $3357-3366$

Buzdar AU (2001b) A summary of second-line randomized studies of aromatase inhibitors. J Steroid Biochem Mol Biol 79: 109-114

Carlini P, Bria E, Giannarelli D, Ferretti G, Felici A, Papaldo P, Fabi A, Nistico C, Di Cosimo S, Ruggeri EM, Milella M, Mottolese M, Terzoli E,
HF, N, V, TEs, VB, and MSP. Thromboembolic phenomena and VB were observed more commonly in Tam-treated patients compared with those receiving $\mathrm{AI}(P=0.01$ and $P=0.001$, respectively), without significant heterogeneity. No significant difference was present between AI vs Tam in terms of HF, N, V, and MSP, without significant heterogeneity. Our findings resembled those already reported in the literature, TE and VB being more frequent with the use of Tam.

Based on the presented results, AI appear to be superior to Tam as first-line endocrine option in postmenopausal women with MBC, as a significant benefit in terms of ORR, CB, and TTP was observed in favour of AI over Tam with fixed effects estimates. Owing to a component of variability between the six studies analysed, the random effects estimates differed from corresponding fixed ones. Concerning the toxicity profile, AI, as expected, caused less thromboembolic phenomena and VB than Tam. Considering our findings, it would be crucial to analyse the cost-utility balance of AI compared with Tam as first-line endocrine treatment of MBC. It has been recently reported (Dranitsaris et al, 2003; Marchetti et al, 2004) that tgAI represent an economically acceptable alternative to Tam. Although investigators should assess heterogeneity of trial results before deriving summary estimates of treatment effect, we think that these findings might be taken into account in the oncology practice during the clinical decision-making process.

\section{ACKNOWLEDGEMENTS}

This work was supported in part by Italian Ministry of Health.
Cognetti F (2005) New aromatase inhibitors as second-line endocrine therapy in postmenopausal metastatic breast cancer patients: a pooled analysis of the randomized trials. Cancer 104(7): 1335-1342

Copur MS, Ledakis P, Bolton M, Norvell M, Muhvic J (2001) Is anastrozole superior to tamoxifen as first-line therapy for advanced breast cancer?: Letter 1. J Clin Oncol 19: 2578

Costa SD, Kaufmann M (2001) Is anastrozole superior to tamoxifen as firstline therapy for advanced breast cancer?: Letter 5. J Clin Oncol 19: 2580 DeFriend DJ, Anderson E, Bell J, Wilks DP, West CM, Mansel RE, Howell A (1994) Effects of 4-hydroxytamoxifen and a novel pure antioestrogen (ICI 182780) on the clonogenic growth of human breast cancer cells in vitro. Br J Cancer 70: 204-211

Di Leo A, Bleiberg H (2003) Overall survival is not a realistic end-point for clinical trials of new drugs in advanced solid tumors: a critical assessment based on recently reported phase III trials in colorectal and breast cancer. J Clin Oncol 21: 2045-2047

Dombernowsky P, Smith I, Falkson G, Leonard R, Panasci L, Bellmunt J, Bezwoda W, Gardin G, Gudgeon A, Morgan M, Fornasiero A, Hoffmann W, Michel J, Hatschek T, Tjabbes T, Chaudri HA, Hornberger U, Trunet PF (1998) Letrozole, a new oral aromatase inhibitor for advanced breast cancer: double-blind randomized trial showing a dose effect and improved efficacy and tolerability compared with megestrol acetate. J Clin Oncol 16: $453-461$

Dranitsaris G, Verma S, Trudeau G (2003) Cost utility analysis of first-line hormonal therapy in advanced breast cancer. Comparison of two aromatase inhibitors to tamoxifen. Am J Clin Oncol 26: 289-296

Engels EA, Schmid CH, Terrin N, Olkin I, Lau J (2000) Heterogeneity and statistical significance in meta-analysis: an empirical study of 125 metaanalyses. Stat Med 19: $1707-1728$

Falkson CI, Falkson HC (1996) A randomised study of CGS 16949A (fadrozole) vs tamoxifen in previously untreated postmenopausal patients with metastatic breast cancer. Ann Oncol 7(5): 465-469

Forbes JF (1997) The control of breast cancer: the role of tamoxifen. Semin Oncol 24: S1 - S5 (S1 - S19)

Greenland S (1987) Quantitative methods in the review of epidemiologicliterature. Epidemiol Rev 9: 1-30

Kaufmann M, Bajetta E, Dirix LY, Fein LE, Jones SE, Zilembo N, Dugardyn JL, Nasurdi C, Mennel RG, Cervek J, Fowst C, Polli A, di Salle E, Arkhipov 
A, Piscitelli G, Miller LL, Massimini G (2000) Exemestane is superior to megestrol acetate after tamoxifen failure in postmenopausal women with advanced breast cancer: results of a phase III randomized double-blind trial - The Exemestane Study Group. J Clin Oncol 18: 1399-1411

Marchetti M, Caruggi M, Colombo G (2004) Cost utility and budget impact of third-generation aromatase inhibitors for advanced breast cancer: a literature-based model analysis of costs in the Italian National Health Service. Clin Ther 26: $1546-1561$

Messori A, Cattel F, Trippoli S, Vaiani M (2000) Survival in patients with metastatic breast cancer: analysis of randomized studies comparing oral aromatase inhibitors vs megestrol. Anticancer Drugs 11: $701-706$

Milla-Santos A, Milla L, Portella J, Rallo L, Pons M, Rodes E, Casanovas J, Puig-Gali M (2003) Anastrozole $v s$ tamoxifen as first-line therapy in postmenopausal patients with hormone-dependent advanced breast cancer: a prospective, randomized, phase III study. Am J Clin Oncol 26: $317-322$

Mouridsen H, Gershanovich M, Sun Y, Perez-Carrion R, Boni C, Monnier A, Apffelstaedt J, Smith R, Sleeboom HP, Jaenicke F, Pluzanska A, Dank M, Becquart D, Bapsy PP, Salminen E, Snyder R, Chaudri-Ross H, Lang R, Wyld P, Bhatnagar A (2003) Phase III study of letrozole $v s$ tamoxifen as first-line therapy of advanced breast cancer in postmenopausal women: analysis of survival and update of efficacy from the International Letrozole Breast Cancer Group. J Clin Oncol 21: 2101-2109

Mouridsen H, Gershanovich M, Sun Y, Perez-Carrion R, Boni C, Monnier A, Apffelstaedt J, Smith R, Sleeboom HP, Janicke F, Pluzanska A, Dank M, Becquart D, Bapsy PP, Salminen E, Snyder R, Lassus M, Verbeek JA, Staffler B, Chaudri-Ross HA, Dugan M (2001) Superior efficacy of letrozole $v s$ tamoxifen as first-line therapy for postmenopausal women with advanced breast cancer: results of a phase III study of the International Letrozole Breast Cancer Group. J Clin Oncol 19: 2596-2606

Nabholtz JM, Buzdar A, Pollak M, Harwin W, Burton G, Mangalik A, Steinberg M, Webster A, von Euler M (2000) Anastrozole is superior to tamoxifen as first-line therapy for advanced breast cancer in postmenopausal women: results of a North American multicenter randomised trial. J Clin Oncol 18: $3758-3776$

Nabholtz JM, Bonneterre J, Buzdar A, Robertson JFR, Thürlimann B (2003) Anastrozole (Arimidex) vs tamoxifen as first-line therapy for advanced breast cancer in postmenopausal women. Survival analysis and updated safety results. Eur J Cancer 39: 1684-1689
Paridaens R, Therasse P, Dirix L, Beex L, Piccart M, Cameron D, Cufer T, Roozendaal K, Nooij M, Mattiacci MR (2004) First line hormonal treatment for metastatic breast cancer with exemestane or tamoxifen in postmenopausal patients - a randomized phase III trial of the EORTC breast group. Proc Am Soc Clin Oncol 23: 6, abstract 515

Parmar MK, Torri V, Stewart L (1998) Extracting summary statistics to perform meta-analyses of the published literature for survival endpoints. Stat Med 17: 2815-2834

Perez Carrion R, Alberola Candel V, Calabresi F, Michel RT, Santos R, Delozier T, Goss P, Mauriac L, Feuilhade F, Freue M et al (1994) Comparison of the selective aromatase inhibitor formestane with tamoxifen as first-line hormonal therapy in postmenopausal women with advanced breast cancer. Ann Oncol 5(Suppl 7): S19-S24

Peto R (1987) Why do we need systematic overviews of randomized trials? Stat Med 6: $233-240$

Takkouche B, Cadarso-Suarez C, Spiegelman D (1999) Evaluation of old and new tests of heterogeneity in epidemiologic meta-analysis. $\mathrm{Am} \mathrm{J}$ Epidemiol 150(2): 206-215

Tominaga T, Adachi I, Sasaki Y, Tabei T, Ikeda T, Takatsuka Y, Toi M, Suwa T, Ohashi Y (2003) Double-blind randomised trial comparing the non-steroidal aromatase inhibitors letrozole and fadrozole in postmenopausal women with advanced breast cancer. Ann Oncol 14: 62-70

Tonkin K (2001) Is anastrozole superior to tamoxifen as first-line therapy for advanced breast cancer?: Letter 4. J Clin Oncol 19: 2579-2580

Thompson SG, Pocock SJ (1991) Can meta-analyses be trusted? Lancet 338: $1127-1130$

Thurlimann B, Beretta K, Bacchi M, Castiglione-Gertsch M, Goldhirsch A, Jungi WF, Cavalli F, Senn HJ, Fey M, Lohnert T (1996) First-line fadrozole HCI (CGS 16949A) vs tamoxifen in postmenopausal women with advanced breast cancer. Prospective randomised trial of the Swiss Group for Clinical Cancer Research SAKK 20/88. Ann Oncol 7: 471-479

Villar J, Mackey ME, Carroli G, Donner A (2001) Meta-analyses in systematic reviews of randomized controlled trials in perinatal medicine: comparison of fixed and random effects models. Stat Med 20: 3635-3647

Vorobiof DA, Kleeberg UR, Perez-Carrion R, Dodwell DJ, Robertson JF, Calvo L, Dowsett M, Clack G (1999) A randomized, open, parallel-group trial to compare the endocrine effects of oral anastrozole (Arimidex) with intramuscular formestane in postmenopausal women with advanced breast cancer. Ann Oncol 10(10): 1219-1225 